The FASEB Journal express article10.1096/fj.02-1092fje. Published online June 3, 2003.

\title{
Multiplex stress resistance in cells from long-lived dwarf mice
}

Shin Murakami, ${ }^{*}, \dot{+}$ Adam Salmon, ${ }^{*, \dagger}$ and Richard A. Miller*,+,;

*Department of Pathology, ${ }^{\dagger}$ Geriatrics Center, and ${ }^{\dagger}$ Institute of Gerontology, University of Michigan Medical School, Ann Arbor, MI; ${ }^{\mathbb{I}}$ Ann Arbor VA Medical Center, Ann Arbor, MI, 48109-0940, USA

Corresponding author: Richard Miller, 5410 CCGCB, Box 0940, 1500 E Medical Center Drive Ann Arbor, MI 48109-0940. E-mail: millerr@umich.edu

\section{ABSTRACT}

Mutations that extend nematode longevity by interference with IGF-I/insulin sensing pathways also lead to resistance to multiple forms of stress. Here, we report that skin-derived fibroblasts from Snell dwarf mice, already known to show increased longevity and delayed aspects of aging, are resistant to multiple forms of cellular stress, including UV light, heat, paraquat, $\mathrm{H}_{2} \mathrm{O}_{2}$, and the toxic metal cadmium. The findings suggest that increases in cellular resistance to stress may mediate extended longevity in mammals.

Key words: aging • cellular stress resistance • fibroblasts • dwarf mouse

I $\mathrm{n}$ Snell dwarf mice, mutation of the pituitary transcription factor (Pit)-1 gene leads to declines in growth hormone and IGF-I, thyroid hormones, and prolactin. This altered hormonal profile leads to dwarfism, deceleration of several aspects of aging, and a $40 \%$ increase in life span $(1,2)$. However, the mechanism by which the altered hormonal profile leads to life extension is unknown.

Life-extending mutants that perturb an insulin/IGF-1 pathway in the nematode Caenorhabditis elegans show increased resistance to multiple forms of stresses, including oxidative stress (3-5), heat (6), UV stress (7), and the heavy metals cadmium and copper (8). It has been proposed that resistance to multiple forms of stresses is the cause of life extension $(7,9)$. Indeed, life span can also be extended either by exposure to mild heat stress, which induces a temporary increase in stress resistance (6), or by reducing oxidative stress through mimetics of superoxide dismutase (SOD) in C. elegans (10).

The aim of the current study was to test the hypothesis that the Snell dwarf mutation, already known to extend life span and delay aspects of aging in mice, also renders cells resistant to a variety of forms of lethal stress. We found that skin-derived fibroblasts from the dwarfs were indeed resistant to a variety of cellular injuries caused by UV light, heat, paraquat, $\mathrm{H}_{2} \mathrm{O}_{2}$, and the toxic metal cadmium. Thus, the altered hormonal profile in the dwarfs causes long-lasting physiological changes in cells, leading to multiplex stress resistance. The results support the theory that modulation of cellular stress resistance regulates life span in mammals. 


\section{MATERIALS AND METHODS}

\section{General procedure}

Tail skin biopsies were taken from $\mathrm{dw} / \mathrm{dw}$ mice bred as the progeny of $(\mathrm{DW} / \mathrm{J} \times \mathrm{C} 3 \mathrm{H} / \mathrm{HeJ})$-dw/+ females and $(\mathrm{DW} / \mathrm{J} \times \mathrm{C} 3 \mathrm{H} / \mathrm{HeJ}) \mathrm{F} 1-\mathrm{dw} / \mathrm{dw}$ males; these sires had been previously treated with growth hormone and thyroxine to increase body size and fertility. Initial cultures were split sixfold or ninefold to create second passage cells, and twofold or threefold dilutions were made at each subsequent passage. Third or fourth passage fibroblasts were used for assessment of cytotoxicity. Cell survival was measured by a test based on metabolic conversion of the dye WST-1 (Roche Applied Science, Indianapolis, IN), using the method specified by the vendor. Cells from each mouse were tested in triplicate at each dose of stressor, and $\mathrm{LD}_{50}$ was calculated as described subsequently.

\section{Assessment of cytotoxicity after exposure to stress}

Approximately 30,000 trypsinized cells were plated in triplicate onto a 96-well microtiter plate in Dulbecco's modified Eagle's medium (high-glucose variant; Gibco-Invitrogen, Carlsbad, CA) supplemented with $20 \%$ heat-inactivated fetal bovine serum, antibiotics $(100 \mathrm{U} / \mathrm{ml}$ penicillin and $100 \mu \mathrm{g} / \mathrm{ml}$ streptomycin; Sigma, St. Louis, MO) and $0.25 \mu \mathrm{g} / \mathrm{ml}$ of fungizone (BiowhittakerCambrex Life Sciences, Walkersville, MD). After a 16- to 18-h overnight incubation in complete medium, the cells were incubated for $\sim 27 \mathrm{~h}$ (ranging from 24 to $30 \mathrm{~h}$ ) in serum-free DMEM supplemented with $2 \%$ bovine serum albumin (BSA; Sigma). Cells were exposed to one of the stresses over a range of doses indicated in the figure legends. For UV stress, the cells in the 96well plates were washed with phosphate-buffered saline (PBS) and then irradiated with UV light $\left(254 \mathrm{~nm}\right.$ at $5.625 \mathrm{~J} / \mathrm{m}^{2} / \mathrm{s}$ ) in $100 \mu$ of Dulbecco's PBS (Biowhittaker-Cambrex Life Sciences). Cell survival was measured $18 \mathrm{~h}$ later by a test based on metabolic conversion of WST-1. Cells from each mouse were tested in triplicate at each dose of stressor. In Figure 2, survival is given as a proportion to the survival of cells in parallel cultures not exposed to the stress. For assessment of resistance to $\mathrm{H}_{2} \mathrm{O}_{2}$, paraquat, and cadmium (Sigma), the cells in the 96-well plates were washed and exposed to the stress agent for $6 \mathrm{~h}$. For the heat stress assay, serum-starved cells were treated briefly with trypsin to release them from the plates. Approximately 30,000 cells were incubated for various intervals at $42^{\circ} \mathrm{C}$ in a PTC-100 programmable thermal controller (MJ Research, Waltham, MA). The heat-exposed cells were then plated onto 96-well plates coated with collagen type 1 (BD Labware, Bedford, MA) to promote cell attachment to the plates, followed by incubation for $18 \mathrm{~h}$. The cells were incubated at $37^{\circ} \mathrm{C}$ at $5 \% \mathrm{CO}_{2}$ in air before measurement of survival.

\section{Calculation of $\mathrm{LD}_{50}$ and statistical analysis}

At each dose of stress, mean survival was calculated for the triplicate wells. The mean survival at each dose was then used to determine the $\mathrm{LD}_{50}$ for each mouse by probit analysis, using NCSS software (NCSS, Kaysville, UT). Probabilities were calculated by two-way ANOVA, using genotype and assay date as predictor variables and $\mathrm{LD}_{50}$ as the dependent variable; the $P$ value shown represents the null hypothesis that genotype has no effect on $\mathrm{LD}_{50}$. 


\section{Quantification of cell cycle}

Flow cytometry analysis was performed to determine the percentage of the cells at each cell cycle. Cells were trypsinized and collected before and after the serum starvation. Approximately $1 \times 10^{6}$ cells were fixed with ice cold ethanol and then were stained with $50 \mu \mathrm{g} / \mathrm{ml}$ of propidium iodide in the presence of $100 \mu \mathrm{g} / \mathrm{ml}$ of RNase A (type I-A). The stained cells were analyzed by flow cytometric analysis. Cells $(10,000-20,000)$ were used to calculate the percentage of each cell cycle phase.

\section{Thymidine uptake assay for fibroblasts}

As in the stress assay, fibroblasts were plated onto 96-well microtiter plates and incubated for 20-24 h. Cells were incubated for another $27 \mathrm{~h}$ in the serum-free DMEM supplemented with $2 \%$ BSA and were then exposed to stress protocols as described previously. Cells were then allowed to recover in complete DMEM for $24 \mathrm{~h} .{ }^{3} \mathrm{H}$-thymidine was added to each well $(0.5 \mathrm{uCi}$ in $10 \mu \mathrm{l})$ in complete DMEM solution. After a 4-h incubation, cells were washed with PBS, released by trypsinization, and harvested onto glass-fiber filters. Incorporation of ${ }^{3} \mathrm{H}$-thymidine was measured by scintillation counting.

\section{RESULTS}

Fibroblasts were grown from tail skin of young dwarf $(\mathrm{dw} / \mathrm{dw})$ mice and from their phenotypically normal littermates $(\mathrm{dw} /+)$. Third or fourth passage cells were arrested at the G0/G1 phase by a 27-h period of serum starvation and were then exposed to agents that induce cellular injury.

Figure 1 shows $\mathrm{LD}_{50}$ values for fibroblasts from dwarf and control mice in responses to each of five forms of stress. Dwarf cells were significantly more resistant to each stress compared with control cells. The effects on $\mathrm{LD}_{50}$ ranged from a $45 \%$ change for UV light to a $180 \%$ change for cadmium, and all were significant by ANOVA at $P<0.01$. Additional details of the statistical analysis are shown in Table 1. Dose-response curves also showed that cells from the dwarf mice were relatively resistant to each stress over a wide dose range (Fig. 2).

The experiments shown in Figure 1 and $\underline{2}$ were conducted using normal and dwarf mice produced as the progeny of $(\mathrm{DW} / \mathrm{J} \times \mathrm{C} 3 \mathrm{H} / \mathrm{HeJ})$-dw/ $/+$ females and $(\mathrm{DW} / \mathrm{J} \times \mathrm{C} 3 \mathrm{H} / \mathrm{HeJ}) \mathrm{F} 1-\mathrm{dw} / \mathrm{dw}$ males. To see whether the effect of the $\mathrm{dw} / \mathrm{dw}$ genotype could be reproduced on a different genetic background, we compared three dwarf and three control littermates bred as the progeny of $\mathrm{DW} / \mathrm{J}-\mathrm{dw} /+$ females and $(\mathrm{C} 3 \mathrm{H} / \mathrm{HeJ} \times \mathrm{DW} / \mathrm{J}) \mathrm{F} 1-\mathrm{dw} / \mathrm{dw}$ males, using UV light, hydrogen peroxide, and cadmium as stress agents. In this experiment, each set of six mice was tested by each of three independent investigators. Mean $\mathrm{LD}_{50}$ values for the dwarf mice were higher than those for control mice for each agent for each investigator (data not shown). We conclude that the effect of the $\mathrm{dw} / \mathrm{dw}$ genotype can be documented on at least two genetic backgrounds.

The WST-1 conversion assay used for Figure 1 and $\underline{2}$ relies on mitochondrial activity as a surrogate for cellular survival. To rule out the possibility that the effects seen in dwarf mice represented some peculiarity in mitochondrial responsiveness, we conducted a series of experiments in which cells were exposed to UV light, hydrogen peroxide, and cadmium; were 
allowed to recover for $24 \mathrm{~h}$; and were then tested for proliferative ability by a thymidine uptake test. Results are shown in Figure 3, which also shows, for comparison, a parallel assay in which the cells were given the same 24-h recovery period, in serum-containing medium, before WST-1 testing. Both approaches confirmed the findings of Figure 1 and $\underline{2}$ by showing that the resistance of dwarf cells to these three stresses is seen regardless of the method used to assess cell viability.

In initial pilot experiments, we had noted that differences in stress resistance between normal and dwarf cells were not apparent unless the exposure to stress was preceded by an interval of culture in serum-free medium (as in the standard protocol shown in Fig. 1, 2, and $\underline{3}$ ). To provide a formal test of the effect of serum-free medium on stress sensitivity, we tested three cultures of dwarf fibroblasts and three of control fibroblasts in parallel, with or without a 27-h exposure to serum-free medium before exposure to UV, peroxide, or cadmium. The results are shown in Table 2. For each of the three agents tested, there was a significant difference between dwarf and normal mice in the standard protocol $(P<0.05$ in each case by unpaired $t$ test $)$ but no significant difference in $\mathrm{LD}_{50}$ for any of the agents when the serum starvation step was omitted. The table shows that the effect of serum starvation is to increase the sensitivity of the cells to the cytotoxic effects of each form of stress (lower $\mathrm{LD}_{50}$ levels) and that the increase in sensitivity is more dramatic in the normal than in the control cultures.

To see whether dwarf and normal fibroblasts differed in their position in the cell cycle, either before or after serum starvation, we used flow cytometric methods to estimate the fraction of cells in G1/G0, S, and G2/M phases. Results are shown in Table 3, as means \pm SD of two independent experiments. Dwarf and normal fibroblasts do not differ in cell cycle position when tested under these conditions. Serum starvation leads, as expected, to some decrease in the proportion of cells in the $\mathrm{S}$ and $\mathrm{G} 2$ phases, but the cultures are not fully quiescent (G1/G0 fractions, $81-83 \%$ ) even after the serum starvation step.

\section{DISCUSSION}

Our results show that fibroblasts from Snell dwarf mice are more resistant than cells of control mice to each of five different forms of cellular stress when tested after a 27-h period of serum starvation. This result can be documented using either of two tests for cellular viability, one based on mitochondrial activity and the other on incorporation of thymidine into DNA, and can be seen in $\mathrm{dw} / \mathrm{dw}$ mice on either of two segregating genetic backgrounds. The differences between dwarf and control cells do not seem to reflect alterations in distribution of the cells with respect to the cell cycle. The data in Table 2 suggest that the differences between dwarf and normal cells reflect differences in the speed, or extent, to which serum withdrawal leads to increases in sensitivity to multiple forms of stress. We are currently examining candidate proteins (by immunoblotting) and candidate genes (by gene expression screening) to try to develop greater insight into the molecular basis for this differential response to serum withdrawal.

Our findings have several interesting implications. First, they support the idea that the extended longevity and delayed aging of Snell dwarf mice may reflect increased resistance of cells to stress. Note that a mutation at the p66-shc locus that renders mouse fibroblasts resistant to UVinduced apoptosis also extends longevity in homozygous mice (11). It will be worthwhile to delineate the steps that connect cellular stress resistance to its pathological result, disease 
resistance, in these and other models of decelerated aging. Second, the data suggest that resistance to multiple varieties of stress may be coordinately regulated by hormone-sensitive pathways in mice. Defining the molecular basis for this coordinate control may lead to important insights into the relation of cellular differentiation to organismal aging, and provide biochemical targets for potential interventions. Ames dwarf mice, similar in many respects to the Snell dwarfs, have higher levels of catalase in liver and kidney compared with nondwarf controls (12), and it will be of interest to determine what other forms of cellular defense may be bolstered in these and other cells in dwarf mice. Third, the data suggest that the stress-resistance property of slow-aging mice extends to cells, such as dermal fibroblasts, that may play little role in resistance in most forms of lethal disease but that are easily accessible and thus useful for tests of genetic and pharmacological anti-geric interventions. Fourth, the parallelism between the worm and mouse results suggests that the connections between cellular stress resistance and modulation of life history trajectories may have ancient evolutionary roots.

\section{ACKNOWLEDGMENTS}

We thank Maggie Vergara for technical assistance. The work was supported by NIH grants P30AG08808, T32-GM07315-21, and T32-AG00114.

\section{REFERENCES}

1. Flurkey, K., Papaconstantinou, J., Miller, R. A., and Harrison, D. E. (2001) Lifespan extension and delayed immune and collagen aging in mutant mice with defects in growth hormone production. Proc. Natl. Acad. Sci. USA 98, 6736-6741

2. Miller, R. A. (2001) Handbook of the Biology of Aging. (Masoro, E. J., and Austad, S. N., eds), pp. 369-395, Academic Press, San Diego, CA

3. Vanfleteren, J. R. (1993) Oxidative stress and ageing in Caenorhabditis elegans. Biochem. J. 292, 605-608

4. Larsen, P. L. (1993) Aging and resistance to oxidative damage in Caenorhabditis elegans. Proc. Natl. Acad. Sci. USA 90, 8905-8909

5. Honda, Y., and Honda, S. (1999) The daf-2 gene network for longevity regulates oxidative stress resistance and Mn-superoxide dismutase gene expression in Caenorhabditis elegans. FASEB J. 13, 1385-1393

6. Lithgow, G. J., White, T. M., Melov, S., and Johnson, T. E. (1995) Thermotolerance and extended life-span conferred by single-gene mutations and induced by thermal stress. Proc. Natl. Acad. Sci. USA 92, 7540-7544

7. Murakami, S., and Johnson, T. E. (1996) A genetic pathway conferring life extension and resistance to UV stress in Caenorhabditis elegans. Genetics 143, 1207-1218

8. Barsyte, D., Lovejoy, D. A., and Lithgow, G. J. (2001) Longevity and heavy metal resistance in daf-2 and age-1 long-lived mutants of Caenorhabditis elegans. FASEB J. 15, $627-634$ 
9. Johnson, T. E., Lithgow, G. J., and Murakami, S. (1996) Hypothesis: Intervensions that inrease the response to stress offer the potential for effective life prolongation and increased health. J. Gerontol. 51A, B392-B395

10. Melov, S., Ravenscroft, J., Malik, S., Gill, M. S., Walker, D. W., Clayton, P. E., Wallace, D. C., Malfroy, B., Doctrow, S. R., and Lithgow, G. J. (2000) Extension of life-span with superoxide dismutase/catalase mimetics. Science 289, 15671569

11. Brown-Borg, H. M., Bode, A. M., and Bartke, A. (1999) Antioxidative mechanisms and plasma growth hormone levels: potential relationship in the aging process. Endocrine 11, $41-48$

12. Migliaccio, E., Giorgio, M., Mele, S., Pelicci, G., Reboldi, P., Pandolfi, P. P., Lanfrancone, L. L., and Pelicci, P. G. (1999) The p66 ${ }^{\text {shc }}$ adaptor protein controls oxidative stress response and life span in mammals. Nature 402, 309-313

Received January 9, 2003; accepted May 7, 2003. 
Stress resistance of serum-starved fibroblasts from normal and Snell dwarf mice

\begin{tabular}{|c|c|c|c|c|c|}
\hline \multirow[t]{2}{*}{ Stress } & \multirow[t]{2}{*}{ Strain } & & \multirow{2}{*}{$\begin{array}{l}\text { Number of } \\
\text { mice }\end{array}$} & $P$ value & \multirow[t]{2}{*}{ Increase } \\
\hline & & Mean \pm SD & & ANOVA & \\
\hline \multirow[t]{2}{*}{ UV light } & Normal & $110 \pm 19\left(\mathrm{~J} / \mathrm{m}^{2}\right)$ & 10 & - & - \\
\hline & Dwarf & $160 \pm 29\left(\mathrm{~J} / \mathrm{m}^{2}\right)$ & 13 & $<0.0001$ & $45 \%$ \\
\hline \multirow[t]{2}{*}{$\mathrm{H}_{2} \mathrm{O}_{2}$} & Normal & $92 \pm 23(\mu \mathrm{M})$ & 6 & - & - \\
\hline & Dwarf & $227 \pm 20(\mu \mathrm{M})$ & 8 & 0.002 & $147 \%$ \\
\hline \multirow[t]{2}{*}{ Paraquat } & Normal & $1.28 \pm 1.13(\mathrm{mM})$ & 7 & - & - \\
\hline & Dwarf & $2.04 \pm 0.90(\mathrm{mM})$ & 10 & 0.01 & $53 \%$ \\
\hline \multirow[t]{2}{*}{ Cadmium } & Normal & $4.5 \pm 3.8(\mu \mathrm{M})$ & 12 & - & - \\
\hline & Dwarf & $12.6 \pm 10.8(\mu \mathrm{M})$ & 15 & 0.007 & $180 \%$ \\
\hline \multirow[t]{2}{*}{ Heat } & Normal & $14.1 \pm 9.4(\mathrm{~min})$ & 8 & - & - \\
\hline & Dwarf & $28.6 \pm 8.6(\mathrm{~min})$ & 11 & 0.006 & $102 \%$ \\
\hline
\end{tabular}

${ }^{a}$ Average $\mathrm{LD}_{50}$ across the set of mice tested. 


\section{Table 2}

\section{Comparison of serum-starved and serum-exposed cultures for stress resistance ${ }^{\mathrm{a}}$}

\begin{tabular}{llcc}
\hline Stress (units) & Strain & \multicolumn{1}{c}{$\begin{array}{l}\text { LD } \\
\text { Starved }\end{array}$} & LD $_{50}$ Not Starved \\
& Normal & $13.8 \pm 8.8$ & $72 \pm 10$ \\
& Dwarf & $40.7 \pm 4.1$ & $100 \pm 6.7$ \\
$\mathrm{H}_{2} \mathrm{O}_{2}(\mu \mathrm{M})$ & Normal & $50 \pm 16$ & $353 \pm 79$ \\
& Dwarf & $135 \pm 34$ & $409 \pm 41$ \\
Cadmium $(\mu \mathrm{M})$ & Normal & $1.3 \pm 0.7$ & $25 \pm 2.2$ \\
& Dwarf & $3.5 \pm 0.4$ & $29 \pm 3.0$ \\
\hline
\end{tabular}

${ }^{a}$ Each value is given as mean $\mathrm{LD}_{50} \pm \mathrm{SE}$ for three individual mice tested in parallel. Serum-starved cultures were treated to the same protocol used for Figure 1 and Figure 2, that is, with a 27-h interval of incubation in serumfree medium before stress exposure. Not starved cultures were exposed to stress without a preceding 27-h incubation in serum-free medium. 


\section{Table 3}

Percentage of the cells at each cell-cycle phase before and after $27 \mathrm{~h}$ of serum starvation ${ }^{\mathrm{a}}$

\begin{tabular}{lccccc}
\hline & \multicolumn{2}{c}{ Normal littermates } & & \multicolumn{2}{c}{$\mathbf{d w} / \mathbf{d w}$} \\
\cline { 2 - 3 } \cline { 5 - 6 } $\begin{array}{l}\text { Cell cycle } \\
\text { and viability }\end{array}$ & Before & Serum Starved & & Before & Serum \\
starvation $(\%)$ & $(\%)$ & & starvation $(\%)$ & Starved $(\%)$ \\
\hline G1/G0 & $75.5 \pm 2.9$ & $82.8 \pm 6.7$ & & $74.8 \pm 4.0$ & $81.0 \pm 3.7$ \\
S & $15.1 \pm 0.7$ & $12.4 \pm 3.7$ & & $15.8 \pm 1.0$ & $13.7 \pm 2.8$ \\
G2 & $9.4 \pm 2.5$ & $4.9 \pm 0.4$ & & $9.5 \pm 1.3$ & $5.4 \pm 1.2$ \\
Dead cells & $2.0 \pm 0.8$ & $3.5 \pm 0.2$ & & $1.7 \pm 1.7$ & $2.5 \pm 0.5$ \\
\hline
\end{tabular}

${ }^{a}$ Mean \pm SD of two experiments. 
Fig. 1
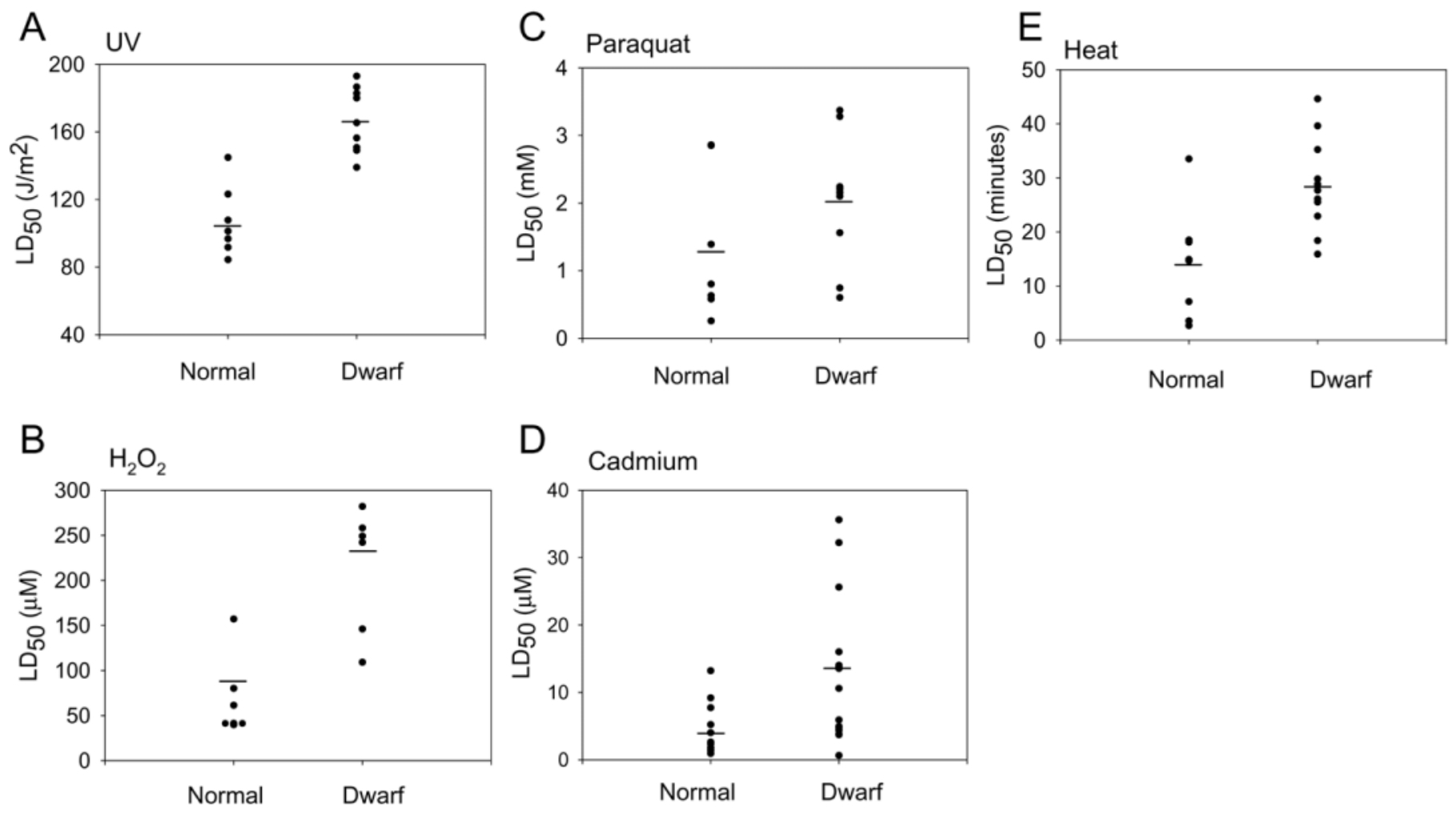

Figure 1. Skin-derived fibroblasts from dwarf mice are resistant to multiple forms of stress. Each symbol in the figure represents an individual mouse of the indicated genotype; the horizontal dash indicates the mean value in each case. The results for each stress are compiled from three to five separate experiments, each containing a balanced number of samples from dwarf and control mice. Percent increases in $\mathrm{LD}_{50}$ and $P$ values were as follows: UV light $(45 \% ; P<0.0001)$, hydrogen peroxide $(147 \% ; P=0.002)$, paraquat $(53 \% ; P=0.01)$, cadmium $(180 \% ; P=0.007)$, and heat $(102 \% ; P=0.006)$. 
Fig. 2
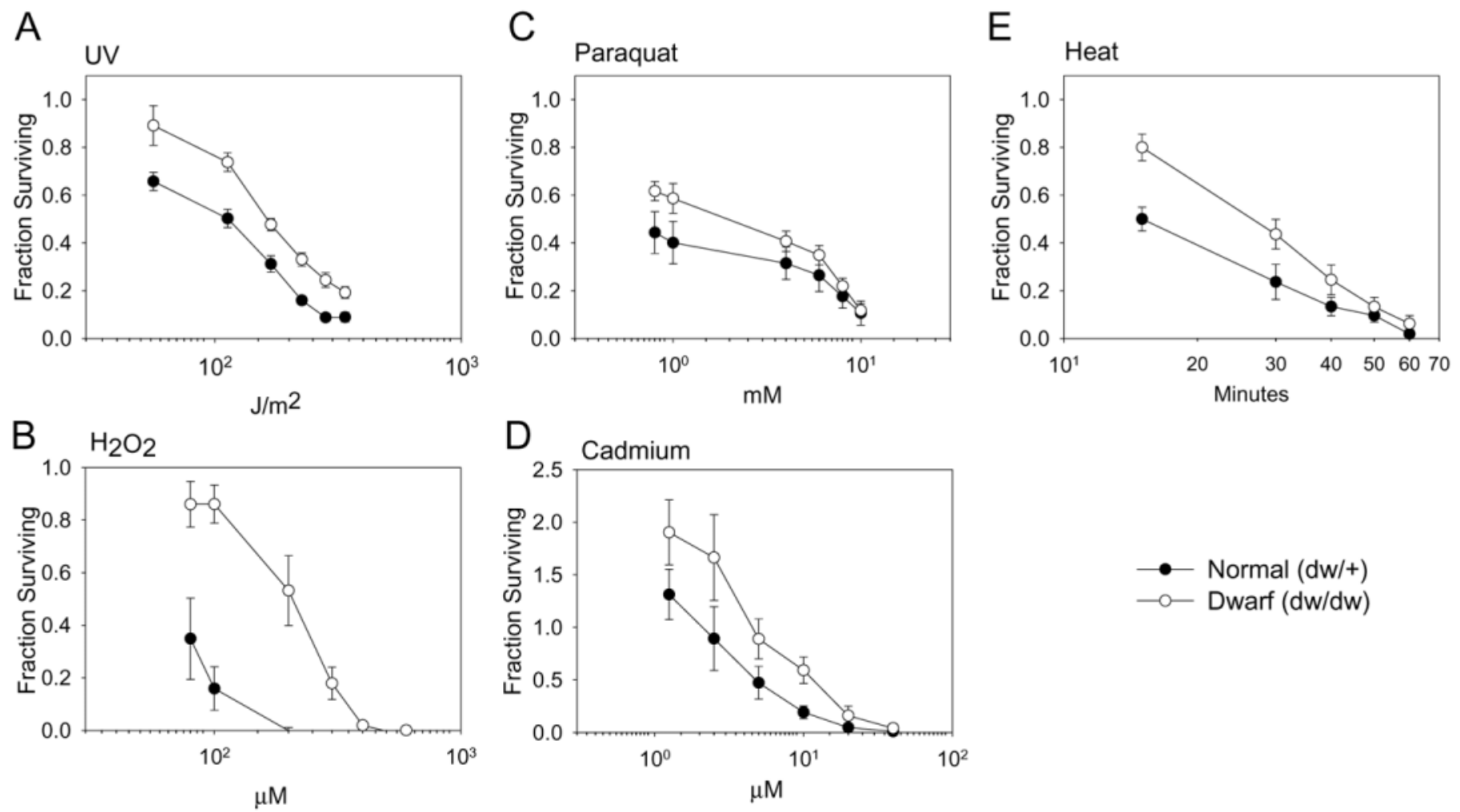

Figure 2. Dose-response curves of the fibroblasts shown in Figure 1. Each symbol shows the mean and SD at the indicated dose across the set of experiments performed. 
Fig. 3
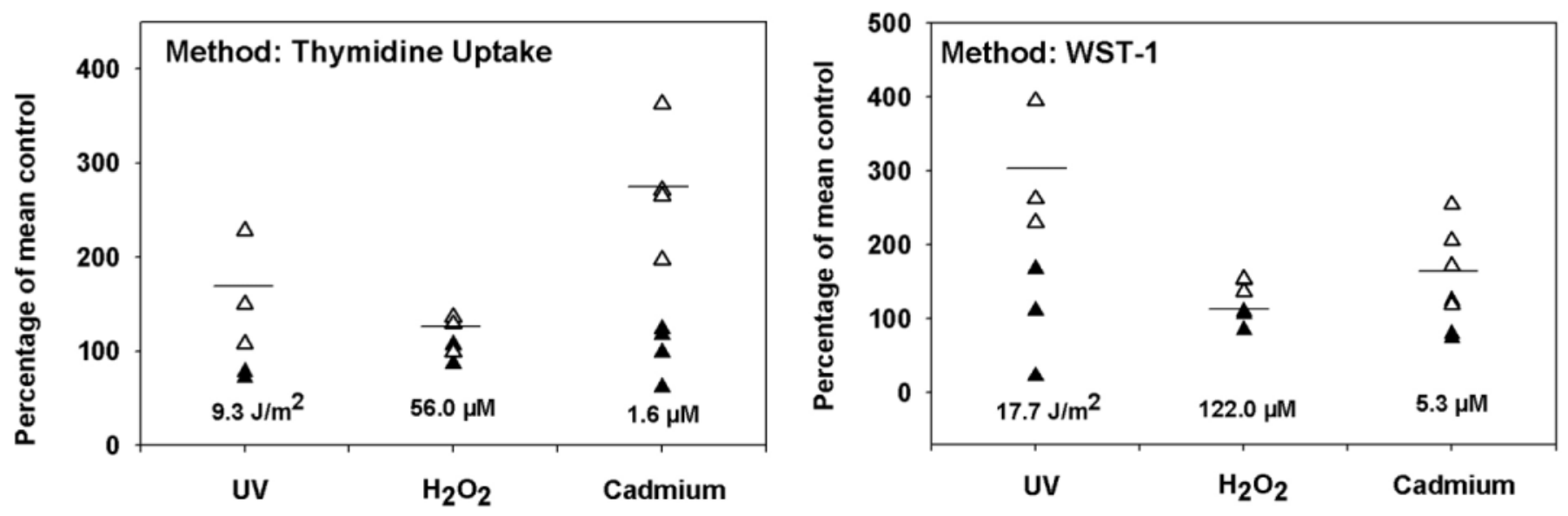

Figure 3. Comparison of WST-1 method (right panel) to thymidine uptake method (left panel) as a measure of cell viability after stress exposure. Three or four dwarf (open symbols) and three or four normal mice (filled symbols) were tested in parallel; each symbol represents $\mathrm{LD}_{50}$ from one mouse, expressed as the percentage of the mean response of the control mice tested. The mean $\mathrm{LD}_{50}$ level for the control mice is shown in each column. The short horizontal lines show the mean values for dwarf mice for each of the stress agents. 